\title{
Rosiglitazone and Pioglitazone Utilization from January 2007 Through May 2008 Associated With Five Risk-Warning Events
}

\author{
Catherine I. Starner, PharmD, BCPS, CGP; Jeremy A. Schafer, PharmD; \\ Alan H. Heaton, PharmD; and Patrick P. Gleason, PharmD, BCPS, FCCP
}

\begin{abstract}
BACKGROUND: Rosiglitazone was approved by the U.S. Food and Drug Administration (FDA) for type 2 diabetes in 1999. The unique mechanism of action and low risk of hypoglycemia contributed to rapid market uptake of rosiglitazone, but safety concerns became more prominent in 2007. There were 5 major events on 4 calendar days in 2007 regarding safety concerns related to rosiglitazone in certain patients: (1) the May 21, 2007, online release of the rosiglitazone meta-analysis performed by Nissen and Wolski and the FDA safety warning on the same day; (2) the July 30, 2007, conclusion of an FDA advisory committee meeting that rosiglitazone increased cardiac ischemic risk; (3) the August 14, 2007, update of thiazolidinedione (TZD) labels with a black-box warning for heart failure; and (4) the November 14, 2007, update to the warnings and precautions section of the rosiglitazone label for coadministration of nitrate or insulin.

OBJECTIVES: To (1) describe TZD (rosiglitazone and pioglitazone) utilization trends from January 1, 2007, continuing through May 2008 amid public announcements of safety concerns and (2) determine the percentage of TZD users who had medical claims indicating increased cardiovascular (CV) risk before and after release (May 21, 2007) of the FDA safety warning and online release of the meta-analysis performed by Nissen and Wolski.
\end{abstract}

METHODS: A retrospective analysis of pharmacy claims was performed from 9 commercial plans with a combined 9 million eligible members, including a 1.4 million-member cohort from 1 of the plans for which medical claims data were available. We evaluated trends in TZD use for each month for the 17-month period from January 1, 2007, through May 31, 2008, including the percentage of TZD users at increased CV risk. In the trend analysis, for each calendar month of 2007 , we calculated mean pharmacy claim counts per day per million members for each of the 2 TZD drugs and for a comparison drug, sitagliptin, a new oral hypoglycemic agent in a different class (dipeptidyl-peptidase-IV inhibitors). For the CV risk analysis, we used the database of integrated medical and pharmacy claims for the 1.4 million-member cohort to identify patients with a current days supply of a TZD on May 20, 2007, December 7, 2007, or May 20, 2008. The medical claims for all identified patients were queried back 2 years from May 20, 2007, December 7, 2007, or May 20, 2008, respectively. Rosiglitazone users at increased CV rsk were defined as those with a medical claim with a primary diagnosis for congestive heart failure (CHF; International Classification of Diseases, Ninth Revision, Clinical Modification [ICD-9-CM] codes 428.xx or 398.91), those with a current supply of nitrate or insulin therapy, or those with ischemic heart disease, including myocardial infarction (MI; ICD-9-CM codes 410.xx through 414.xx, or surgical procedure codes [36.0x through $36.3 \mathrm{x}$ for removal of obstruction and insertion of stents, bypass surgery, and revascularization] in the primary diagnosis field). Pioglitazone users at increased risk were identified from medical claims with a CHF diagnosis code.

RESULTS: The average number of claims per day per million members in January 2007 was 97.3 for rosiglitazone and 107.2 for pioglitazone. The average number of claims for rosiglitazone per day per million members began to decrease in May 2007, falling to 41.0 in December 2007, for a total decrease of $58.6 \%$ from the February 2007 peak (99.1), and fell further to 31.8 in May 2008. Pioglitazone use increased $8.0 \%$ from January to June 2007 (107.2 to 115.8) and remained relatively flat through December 2007
(114.6) and through May 2008 (108.9). Sitagliptin claims increased 5-fold, at a consistent rate, from an average of 8.6 claims per day per million members in January 2007 to 43.4 in December 2007, and continued to increase to 48.7, in May 2008. Of the 5,117 rosiglitazone users on May 20, $2007,1,296(25.3 \%)$ were identified at increased CV risk versus 590 $(22.5 \%)$ of 2,621 users on December 7, $2007(P=0.006)$, and $336(21.8 \%)$ of 1,541 users in May $2008(P=0.005)$. Of 6,056 pioglitazone users on May 20, 2007, $170(2.8 \%)$ had a CHF diagnosis versus $160(2.5 \%)$ of 6,275 users on December 7, $2007(P=0.376)$, and 122 of 5,998 users in May $2008(P=0.006)$.

CONCLUSIONS: Although rosiglitazone utilization per million members declined by more than half in 2007, when CV safety concerns started to emerge, about 1 in 5 rosiglitazone users had elevated CV risk at year-end 2007 and in May 2008. About 3\% of pioglitazone users in May 2007 had a diagnosis of CHF in claims history, which declined to 2\% in May 2008. Insurers should consider the impact of persistent utilization of TZDs among members with CV risk factors when making formulary decisions.

J Manag Care Pharm. 2008;14(6):523-31

Copyright $\odot$ 2008, Academy of Managed Care Pharmacy. All rights reserved.

\section{What is already known about this subject}

- The label of rosiglitazone, 1 of 2 thiazolidinediones (TZDs) for use in diabetes, was updated twice in 2007 with additional cardiovascular (CV) risk warnings. The U.S. Food and Drug Administration (FDA) required updates to rosiglitazone prescribing information in August 2007 in a black-box warning regarding congestive heart failure (CHF) and in November 2007 regarding precautions about coadministration of rosiglitazone with insulin or nitrates.

- Pioglitazone had an FDA-required prescribing update with a black-box warning for risk of CHF in August 2007. However, unlike rosiglitazone, pioglitazone has no myocardial ischemic warnings and no warnings for coadministration with insulin or nitrates.

Note: This article is discussed in an editorial on pages 563-70 of this issue. 


\section{What this study adds}

- This is the first TZD utilization report in the literature following the drug label changes in 2007 regarding increased CV risks. We found a $54.0 \%$ decrease in utilization of rosiglitazone between May 2007 and December 2007 and a 1.2\% increase in pioglitazone during the same time period, when both agents were on the preferred drug list (PDL) with the same copayment amount and without formulary guideline differences for the 2 TZDs.

- After rosiglitazone was removed from the commercial national PDL in January 2008, rosiglitazone use continued to decline, to a mean 31.8 claims per day per million members in May 2008, a drop of $67.9 \%$ from peak utilization of 99.1 in February 2007.

- Despite the large reduction in claims per million members, slightly more than 1 in 5 rosiglitazone users had evidence of risk for a CV event in December 2007, and in May 2008. Approximately 1 in 36 pioglitazone users had evidence of CHF in May 2007, which declined to about in 1 in 50 users in May 2008.

- The 5,117 rosiglitazone users in May 2007, 2,621 rosiglitazone users in December 2007, and 1,541 users in May 2008 were categorized into 4 mutually exclusive $\mathrm{CV}$ risk groups, only one of which exhibited a significant change; $2.8 \%$ of users in May 2007 had a medical claim for CHF versus 2.4\% in December 2007 and 1.7\% in May 2008 ( $P=0.015$ ). Prevalence rates for the other 3 risk factors were essentially unchanged among rosiglitazone users in May 2008 compared with May 2007; 2.7\% in May 2007 and May 2008 had a current supply of a nitrate drug ( $P=0.982), 13.1 \%$ had a current supply of insulin versus $11.3 \%$ in May $2008(P=0.057)$, and $6.7 \%$ had a medical claim for a primary diagnosis of ischemic heart disease versus $6.1 \%$ in May $2008(P=0.432)$.

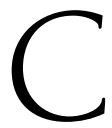

onsensus guidelines developed by the American Diabetes Association (ADA) and the European Association for the Study of Diabetes (EASD) identify thiazolidinediones (TZDs) as a second-line option after lifestyle modifications and the maximum tolerated dose of metformin are not effective. ${ }^{1}$ The TZDs received U.S. Food and Drug Administration (FDA) approval in 1999. Their unique mechanism of action and low risk of hypoglycemia contributed to rapid market uptake. In the first full year on the U.S. market in 2000, rosiglitazone ranked $\# 40$ in community pharmacy sales ( $\$ 618$ million), and pioglitazone ranked \#47 with $\$ 551$ million in sales. ${ }^{2}$ In 2006 , rosiglitazone and pioglitazone rose to rank $\# 17$ and $\# 14$, with approximately $\$ 1.664$ billion and $\$ 1.926$ billion in community pharmacy sales, respectively. ${ }^{2}$ The increase in the utilization of TZDs between 2000 and 2006 may have, in part, been fueled by their purported potential to reduce cardiovascular (CV) event risk..$^{3-6}$
Although low hypoglycemic risk and potential CV benefits may have propelled TZD use and sales, congestive heart failure (CHF) safety concerns were known at the time of FDA approval of both TZDs. ${ }^{7-10}$ Furthermore, the ADA published a consensus statement in 2004 warning health care professionals of the risk factors for TZD-induced heart failure, which included (but were not limited to) a history of heart failure, history of prior myocardial infarction (MI), or symptomatic coronary artery disease, and insulin coadministration. ${ }^{11}$ In May 2007, the CV risk associated with rosiglitazone expanded beyond CHF when 2 metaanalyses were published indicating that rosiglitazone may be associated with an increased risk of MI (Table 1). The first study was published online on May 21, 2007, in which Nissen and Wolski evaluated 42 randomized clinical trials and found that rosiglitazone was associated with 1.43 (95\% confidence interval $[C I]=1.03-1.98 ; P=0.03)$ times increased risk of MI compared with treatment that did not include rosiglitazone; however, death from a CV cause was not statistically significant. ${ }^{12}$ The second study was a rosiglitazone meta-analysis performed by the drug's manufacturer using the same data, finding a nearly identical significantly increased risk of myocardial ischemia (1.31; 95\% $\mathrm{CI}=1.01-1.70){ }^{13}$

In response to growing CV safety signals, on July 30, 2007, the FDA held a joint meeting of the Endocrinologic and Metabolic Drugs Advisory Committee and the Drug Safety and Risk Management Advisory Committee to discuss the current rosiglitazone evidence. ${ }^{14}$ The joint committee agreed that the available data supported a conclusion that rosiglitazone use was associated with increased cardiac ischemia risk; however, the committee concluded that the overall risk-benefit profile of rosiglitazone supported leaving the drug on the market. ${ }^{15}$ The minutes of the advisory meeting also reflect that: "The committee further identified subpopulations at potential risk, such as nitrate users, those with established cardiovascular disease, and those with coexisting insulin therapy, who appeared to have an increased risk." ${ }^{16}$ The committee raised concerns about the quality of the meta-analysis data, including short duration of the trials, low number of cardiac events, and study heterogeneity.

On August 14, 2007, a new boxed warning was added to both TZD labels notifying health care professionals of the increased CHF risk. In November 2007, rosiglitazone's manufacturer made further safety warning label changes. The updated rosiglitazone label includes the following statement: "A meta-analysis of 42 clinical studies (mean duration 6 months; 14,237 total patients), most of which compared Avandia to placebo, showed Avandia to be associated with an increased risk of myocardial ischemic events such as angina or MI. Three other studies (mean duration 41 months; 14,067 patients), comparing Avandia to some other approved oral antidiabetic agents or placebo, have not confirmed or excluded this risk. In their entirety, the available data on the risk of myocardial ischemia are inconclusive."17 In addition, the rosiglitazone label warnings and precautions 
Rosiglitazone and Pioglitazone Utilization from January 2007 Through May 2008 Associated With Five Risk-Warning Events

TABLE 1 Description of Five Major Public Events Regarding Thiazolidinediones in 2007

\begin{tabular}{l|l|l}
\hline Date & \multicolumn{1}{|c|}{ Event } & \multicolumn{1}{c}{ Substance } \\
\hline May $21^{12,26}$ & Nissen and Wolski rosiglitazone meta-analysis and FDA safety alert on Avandia ${ }^{a}$ & Rosiglitazone \\
\hline July $30^{14}$ & FDA advisory committee meeting & Rosiglitazone \\
\hline August $14^{27}$ & $\begin{array}{l}\text { Prescribing information updated with a black-box warning for exacerbation and precipitation } \\
\text { of heart failure }\end{array}$ & Rosiglitazone and pioglitazone \\
\hline November $14^{28}$ & $\begin{array}{l}\text { Prescribing information updated warnings and precaution section for coadministration of } \\
\text { nitrate or insulin }{ }^{c}\end{array}$ & Rosiglitazone \\
\hline
\end{tabular}

a The FDA Safety Alert released on May 21, 2007, included warning of a "potentially significant increase in the risk of heart attack and heart-related deaths in patients taking Avandia." FDA News. FDA Issues Safety Alert on Avandia. Available at: www.fda.gov/bbs/topics/NEWS/2007/NEW01636.html.

b The label changes for rosiglitazone and pioglitazone described in the FDA Alert (Information for Healthcare Professionals) on August 14, 2007, included a new black-box warning: "Fluid retention, weight gain, edema, and heart failure are known side-effects of TZDs. Continued post-marketing reports of heart failure have prompted the FDA to increase the prominence of this safety concern in the labels for these drugs. This cardiovascular concern is separate from a recent concern of increased myocardial ischemia risk." The new FDA recommendations and considerations included the language: Thiazolidinediones, including Actos, Actoplus Met, Duetact, Avandia, Avandamet, and Avandaryl: (1) may cause or exacerbate congestive heart failure in some patients; (2) initiation of these drugs in patients with established NYHA Class III or IV heart failure is contraindicated; (3) after initiation of these drugs, and after dose increases, observe patients carefully for signs and symptoms of heart failure (including excessive, rapid weight gain; dyspnea; and/or edema); and (4) if these signs and symptoms develop and heart failure is confirmed, appropriate management of heart failure should be initiated. Discontinuation or dose reduction of these drugs should be considered.

c The label changes for rosiglitazone only on 11/14/07 included the language: Rosiglitazone may cause myocardial ischemia in some patients. Coadministration of rosiglitazone and insulin is not recommended. A higher risk of myocardial ischemia was observed in controlled, double-blind clinical trials, where rosiglitazone was added on to established insulin therapy. Rosiglitazone is not recommended for patients with heart disease who are taking nitrates. A subgroup analysis of 42 clinical studies identified that patients with heart disease who are taking nitrates are at an increased risk of myocardial ischemia.

FDA =U.S. Food and Drug Administration; TZDs = thiazolidinediones.

section was updated, stating that coadministration of rosiglitazone with nitrates or insulin is not recommended. ${ }^{17}$ Of note, the pioglitazone label does not contain any references to myocardial ischemia safety concerns or any coadministration warnings.

Pharmacy benefit managers and health care professionals are presented with a difficult choice on how to address the safety concerns about rosiglitazone. Delays in modification of formulary guidelines could put some patients at risk, but restricting use might deprive some patients of a therapeutic option or result in disruption of therapy for other patients. Analysis of utilization claims data trends and the prevalence of rosiglitazone utilization among high-risk patients permits determination of the possible implications of changes in formulary treatment guidelines.

The primary objectives of this study were to (a) determine the percentage of TZD (rosiglitazone or pioglitazone) users who had medical claims indicating increased CV risk before and after the May 21, 2007, Nissen and Wolski rosiglitazone meta-analysis, and (b) describe TZD utilization trends in light of new safety concerns.

\section{Methods}

The first part of our analysis used retrospective administrative pharmacy claims from 9 commercial BlueCross BlueShield plans, with a combined 9 million eligible members. Pharmacy claims were analyzed to study the potential influence of major events on rosiglitazone and pioglitazone utilization. The assigned Generic Product Identifier (GPI, Medi-Span) was used to identify drug products with GPI codes that start with 27607060 (rosiglitazone), 2799780260 (rosiglitazone with glimepiride), 2799800260 (rosiglitazone with metformin), 27607050 (pioglitazone), 2799780240 (pioglitazone with glimepiride), and 2799800240 (pioglitazone with metformin). The average number of claims for rosiglitazone and pioglitazone per day per million members were calculated for each month from January 1, 2007, through May 2008. For example, rosiglitazone claims per day peaked in February 2007 at 897.2, so average claims per day per million members would be 99.1 (897.2 claims/9,054,886 members $\times 1,000,000)$ for that month. We did not adjust claims for mail order or claims with a 60- or 90-day supply.

We identified 5 major events on 4 calendar days in 2007 regarding safety concerns related to rosiglitazone in certain patients: (1) the May 21, 2007, online release of the rosiglitazone meta-analysis performed by Nissen and Wolski and the FDA safety warning on the same day; (2) the July 30, 2007, conclusion of an FDA advisory committee meeting that rosiglitazone increased cardiac ischemic risk; (3) the August 14, 2007, update of TZD labels with a black-box warning for heart failure; and (4) the November 14, 2007, update to the warnings and precautions section of the rosiglitazone label for coadministration of nitrate or insulin. The August 14, 2007, FDA warning and label change affected pioglitazone as well as rosiglitazone.

Sitagliptin claims (including combination products) for the same period were included as a reference comparison using the same methodology. The sitagliptin single-agent entity was 
approved by the FDA on October 16, 2006 (GPI starts with 2755), and the combination sitagliptin with metformin was approved by the FDA on March 30, 2007 (GPI starts with 27992502). ${ }^{18,19}$

The second part of our analysis used retrospective administrative medical and pharmacy claims from a 1.4 million member subgroup of our 9 million eligible members. Three separate cohorts of members, 1 with members having a rosiglitazone supply and another with members having a pioglitazone supply on May 20, 2007 (1 day prior to the Nissen and Wolski rosiglitazone meta-analysis publication release), were identified. This same analysis was repeated with the requirement of a rosiglitazone or pioglitazone supply on December 7, 2007 (approximately 6 months after the release of the results of the Nissen and Wolski rosiglitazone meta-analysis). A final analysis was repeated with the requirement of a rosiglitazone or pioglitazone supply on May 20, 2008 (1 year after the initial cohort analysis), for a total of 6 cohorts. We defined use of rosiglitazone and pioglitazone on May 20, 2007, December 7, 2007, or May 20, 2008, using the member's claim, the date filled, and the days supply entered on the claim. For the May 20, 2007, analysis, all identified members' medical claims were queried from May 21, 2005, through May 20, 2007. For the December 7, 2007, analysis, the medical claims for all identified members were queried from December 8, 2005, through December 7, 2007. For the May 20, 2008, analysis, all identified members' medical claims were queried from May 21 , 2006, through May 20, 2008. Members were not required to be continuously enrolled. Medical claims were searched for a diagnosis of CHF (International Classification of Diseases, Ninth Revision, Clinical Modification [ICD-9-CM] codes 428.xx and 398.91), or ischemic heart disease (IHD; ICD-9-CM codes 410.xx through 414.xx, or surgical procedure codes [36.0x through 36.3x for removal of obstruction and insertion of stents, bypass surgery, and revascularization]) in the primary diagnosis field. In addition to evaluation of the medical claims, these members' pharmacy claims were queried for the presence of a current days supply of a nitrate (GPI beginning with 3210) and/or insulin (GPI beginning with 2710) on May 20, 2007, December 7, 2007, or May 20, 2008; in other words, the fill date on the claim had to have a sufficient days supply for the patient to have insulin and/or nitrate on hand on May 20, 2007, December 7, 2007, or May 20, 2008.

The assessment of a CHF or IHD medical claim diagnosis and the nitrate or insulin pharmacy supply were selected because of the FDA advisory committee meeting minutes. Further categorization of members was done to create a mutually exclusive hierarchical grouping ranked as $\mathrm{CHF}$, nitrate, insulin, or IHD. For example, a patient with a medical diagnosis of $\mathrm{CHF}$ and a current supply of insulin would be classified in the CHF category. Members with neither the presence of a primary diagnosis on a medical claim for CHF or IHD nor a pharmacy supply of nitrate or insulin were defined as not having claims data to indicate increased potential cardiac risk. Statistical comparisons were performed using the Pearson chi-square analysis for the within- drug proportions at increased risk before and after release of the meta-analysis by Nissen and Wolski. Statistical significance was set at $P<0.01$ to account for multiple comparisons. (SAS Institute Inc., Cary, NC)

\section{Results}

Pioglitazone, rosiglitazone, and sitagliptin were all on the preferred drug list (PDL) of the 2007 drug formulary. The pioglitazone, rosiglitazone, and sitagliptin trends in the average number of claims per day per million members from January 1 , 2007, through May 31, 2008, are presented in the Figure. The mean number of rosiglitazone claims (including combination products) per day per million members was 97.3 in January 2007 and peaked in February 2007 at 99.1 claims per day per million members. There was a decline in the mean number of claims from 98.8 in April to 89.1 in May, associated with the release of the Nissen and Wolski rosiglitazone meta-analysis on May 21, 2007. The decline in rosiglitazone claims continued to 41.0 average claims per day per million members in December 2007, a decrease of 58.5\% from the peak of 99.1 claims in February 2007, and decreased by $67.8 \%$ to 31.8 in May 2008 .

Prior to the May 2007 Nissen and Wolski rosiglitazone metaanalysis, the counts of pioglitazone claims (including combination products) were relatively flat, varying from an average of 107.2 to 108.3 claims per day per million members from January through April. Pioglitazone claims increased $4.3 \%$ in May and another $2.3 \%$ in June, reaching 115.8 average claims per day per million members. From July through December 2007, the trend in pioglitazone average claims per day per million members was flat, with a 4.5\% dip during September, which rebounded slightly in the period from October through December. From January to May 2008, pioglitazone claims decreased another 4.3\% (113.8 to 108.9). Sitagliptin claims increased 5-fold, at a consistent rate, beginning at 8.6 average claims per day per million members in January and ending at 43.4 in December. The rise in sitagliptin slowed from January to May 2008 and ended at 48.7, a 9.7\% increase.

Between May 20, 2007, and December 7, 2007, the number of members with a rosiglitazone supply decreased by $48.8 \%$, from 5,117 users to 2,621 users and dropped further to 1,541 users in May 2008, a 69.9\% reduction in the number of rosiglitazone users (Table 2). Of the 5,117 members with a rosiglitazone supply on May 20, 2007, 1,296 (25.3\%) met the criteria for increased CV risk (i.e., medical claim for CHF or IHD or current supply of insulin or nitrate). The most prevalent risk factor was current insulin use, present in 672 (13.1\%) rosiglitazone users. On December 7, 2007, 2,621 members had a rosiglitazone supply. A CV risk factor was present in 590 (22.5\%) of those members, with current insulin use being the most common risk factor found in 307 (11.7\%) rosiglitazone users. The only notable difference in May 2008 compared with December 2007 was that the use of rosiglitazone in members with a medical claim for $\mathrm{CHF}$ was even lower $(1.7 \%$ 


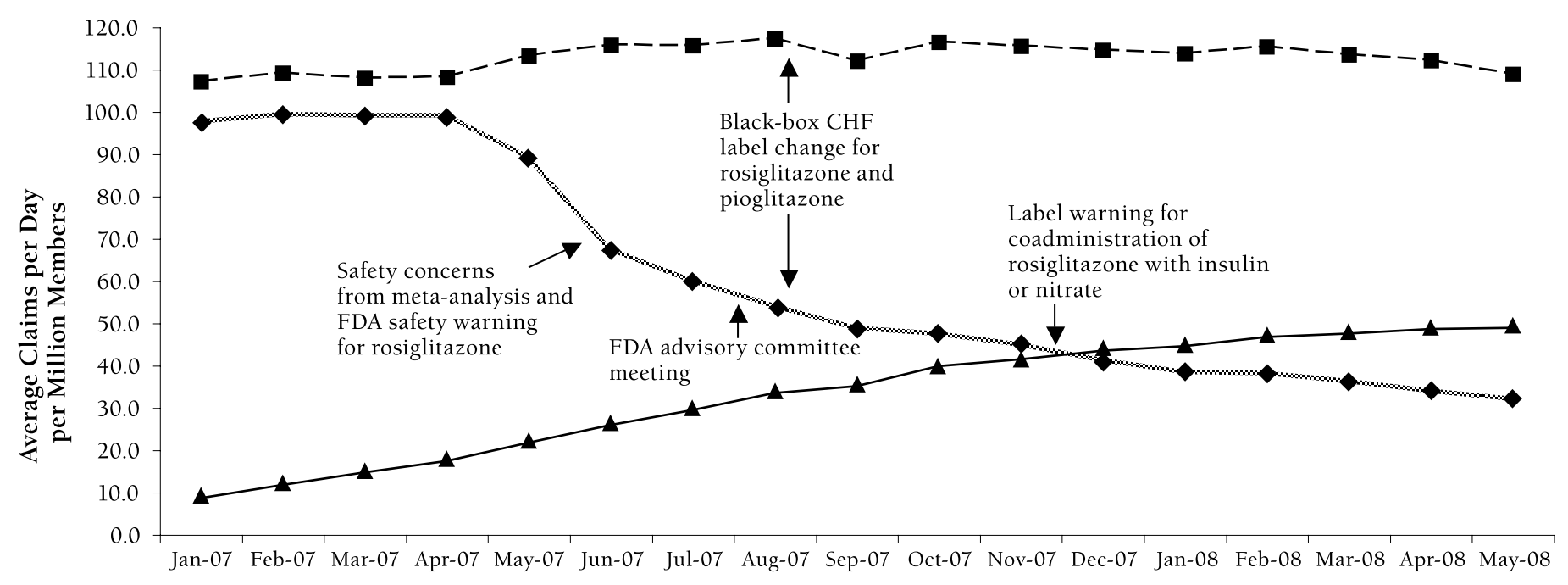

$-\rightarrow-$ pioglitazone rosiglitazone $\longrightarrow$ sitagliptin

\begin{tabular}{|c|c|c|c|c|c|c|c|c|c|c|c|c|c|c|c|c|c|}
\hline Drug & $\begin{array}{c}\text { Jan } \\
07\end{array}$ & $\begin{array}{c}\text { Feb } \\
07\end{array}$ & $\begin{array}{c}\text { Mar } \\
07\end{array}$ & $\begin{array}{c}\text { Apr } \\
07\end{array}$ & $\begin{array}{c}\text { May } \\
07\end{array}$ & $\begin{array}{c}\text { Jun } \\
07\end{array}$ & $\begin{array}{c}\text { Jul } \\
07\end{array}$ & $\begin{array}{c}\text { Aug } \\
07\end{array}$ & $\begin{array}{c}\text { Sep } \\
07\end{array}$ & $\begin{array}{c}\text { Oct } \\
07\end{array}$ & $\begin{array}{c}\text { Nov } \\
07\end{array}$ & $\begin{array}{c}\text { Dec } \\
07\end{array}$ & $\begin{array}{c}\text { Jan } \\
08 \\
\end{array}$ & $\begin{array}{c}\text { Feb } \\
08\end{array}$ & $\begin{array}{c}\text { Mar } \\
08\end{array}$ & $\begin{array}{c}\text { Apr } \\
08\end{array}$ & $\begin{array}{c}\text { May } \\
08\end{array}$ \\
\hline Pioglitazone & 107.2 & 109.2 & 108.0 & 108.3 & 113.2 & 115.8 & 115.7 & 117.3 & 112.0 & 116.4 & 115.5 & 114.6 & 113.8 & 115.4 & 113.6 & 112.2 & 108.9 \\
\hline Rosiglitazone & 97.3 & 99.1 & 98.7 & 98.8 & 89.1 & 67.1 & 59.7 & 53.1 & 48.5 & 47.2 & 44.5 & 41.0 & 38.1 & 37.9 & 36.0 & 33.7 & 31.8 \\
\hline Sitagliptin & 8.6 & 11.7 & 14.6 & 17.4 & 21.7 & 25.8 & 29.3 & 33.4 & 35.1 & 39.8 & 41.4 & 43.4 & 44.4 & 46.6 & 47.5 & 48.5 & 48.7 \\
\hline
\end{tabular}

ancludes combination products containing rosiglitazone, pioglitazone, or sitagliptin.

$\mathrm{CHF}=$ congestive heart failure; FDA=U.S. Food and Drug Administration.

compared with 2.4\%). Current supply of insulin continued to be the most common risk factor (174 [11.3\%]). No individual risk factor's prevalence changed significantly over the 6 months. The overall proportion of rosiglitazone users without a risk factor increased an absolute 3.5\%, from $74.7 \%$ to $78.2 \%(P=0.005)$.

From May 20, 2007, to May 20, 2008, the number of members with a pioglitazone supply decreased by $1.0 \%$ (6,056 to 5,998 ; Table 3). The cardiac risk factor CHF was present in 170 (2.8\%) pioglitazone users in May 2007 and 122 (2.0\%) on May 20, 2008 $(P=0.006)$.

\section{Discussion}

Given the widespread use of TZDs and the heightened safety concerns, it is important to understand current utilization trends and the influence changes to the label may have had on the user demographics. To our knowledge, this is the first TZD utilization report after $\mathrm{CV}$ safety labeling changes and the first to assess the prevalence of CV risk factors among TZD users. The current study adds to our understanding of rosiglitazone users who may be at increased CV risk, providing health insurers with real-world data and allowing them to make more insightful health coverage determinations.

We found rosiglitazone utilization declined immediately after the May 2007 release concerning CV safety data, with a 33.0\% decrease from May 2007 to July 2007. From July to December, use decreased only an additional $31.3 \%$, despite an FDA committee report and 2 label changes with added safety warnings during that time frame. The rosiglitazone decrease in use is similar to 
Rosiglitazone and Pioglitazone Utilization from January 2007 Through May 2008 Associated With Five Risk-Warning Events

\section{TABLE 2 Rosiglitazone Users and Presence of Cardiovascular Risk Factors_Pre- and Post-Safety Concerns}

\begin{tabular}{|c|c|c|c|c|c|c|}
\hline Risk Factor & $\begin{array}{c}\text { May } 2007 \\
\%(n) \text { Patients } \\
(\mathrm{N}=5,117)\end{array}$ & $\begin{array}{c}\text { Dec } 2007 \\
\% \text { (n) Patients } \\
(\mathrm{N}=2,621)\end{array}$ & $\begin{array}{c}\text { May } 2007 \\
\text { vs. Dec } 2007 \\
P \text { Value }^{\mathrm{a}}\end{array}$ & $\begin{array}{c}\text { May } 2008 \\
\%(n) \text { Patients } \\
(\mathrm{N}=1,541)\end{array}$ & $\begin{array}{c}\text { May } 2007 \\
\text { vs. May } 2008 \\
P \text { Value }^{\mathrm{a}}\end{array}$ & $\begin{array}{l}\text { Risk Factor Included } \\
\text { in Package Insert }\end{array}$ \\
\hline Congestive heart failure ${ }^{b, c}$ & $\begin{array}{l}2.8 \% \\
(143)\end{array}$ & $\begin{array}{c}2.4 \% \\
(63)\end{array}$ & 0.312 & $\begin{array}{l}1.7 \% \\
(26)\end{array}$ & 0.015 & $\begin{array}{l}\text { Yes-as of August } 2007 \\
\text { (black box), and prior to } \\
\text { August 2007, it was a warning }\end{array}$ \\
\hline Current supply of nitrate drugb,d & $\begin{array}{l}2.7 \% \\
(140)\end{array}$ & $\begin{array}{c}2.8 \% \\
(74)\end{array}$ & 0.825 & $\begin{array}{r}2.7 \% \\
(42)\end{array}$ & 0.982 & $\begin{array}{l}\text { Yes-as of November } 2007 \\
\text { (warnings and precautions section) }\end{array}$ \\
\hline Current supply of insulin b,d & $\begin{array}{l}13.1 \% \\
(672) \\
\end{array}$ & $\begin{array}{l}11.7 \% \\
(307)\end{array}$ & 0.075 & $\begin{array}{l}11.3 \% \\
(174)\end{array}$ & 0.057 & $\begin{array}{l}\text { Yes-as of November } 2007 \\
\text { (warnings and precautions section) }\end{array}$ \\
\hline Ischemic heart disease $^{b}$ & $\begin{array}{l}6.7 \% \\
(341) \\
\end{array}$ & $\begin{array}{l}5.6 \% \\
(146) \\
\end{array}$ & 0.060 & $\begin{array}{l}6.1 \% \\
(94) \\
\end{array}$ & 0.432 & No \\
\hline Total with risk factor(s) & $\begin{array}{l}25.3 \% \\
(1,296)\end{array}$ & $\begin{array}{l}22.5 \% \\
(590)\end{array}$ & 0.006 & $\begin{array}{c}21.8 \% \\
(336)\end{array}$ & 0.005 & \\
\hline No risk factore & $\begin{array}{l}74.7 \% \\
(3,821)\end{array}$ & $\begin{array}{l}77.5 \% \\
(2,031)\end{array}$ & 0.006 & $\begin{array}{l}78.2 \% \\
(1,205)\end{array}$ & 0.005 & \\
\hline
\end{tabular}

Note: totals may not sum to $100 \%$ due to rounding.

a Pearson chi-square test.

${ }^{\mathrm{b}}$ Increased risk of congestive heart failure is a black-box warning for both rosiglitazone and pioglitazone. ${ }^{13,21}$ Ischemic heart disease and concomitant nitrate and insulin are additional warnings only for rosiglitazone..$^{13}$

${ }^{c}$ Congestive heart failure and ischemic heart disease defined as a medical claim in the prior 2 years with ICD-9-CM codes $428 . x x$ or 398.91 or codes $410 . x x$ through

414.xx or surgical procedure code $36.0 x$ through $36.3 x$ in the primary diagnosis field.

dPharmacy claim with a current supply identified by generic product identifiers beginning with 3210 for nitrate and 2710 for insulin.

e 99 (1.9\%) on May 20, 2007, 58 (2.2\%) on December 7, 2007, and 59 (3.8\%) on May 20, 2008, members did not have any medical claims in the prior 2 years.

ICD-9-CM=International Classification of Diseases, Ninth Revision, Clinical Modification.

\section{TABLE 3 Pioglitazone Users and Presence of Cardiovascular Risk Factors-Pre- and Post-Safety Concerns}

\begin{tabular}{l|c|c|c|c|c|c}
\hline & $\begin{array}{c}\text { May 2007 } \\
\text { Risk Patients } \\
(\mathbf{N}=6,056)\end{array}$ & $\begin{array}{c}\text { Dec 2007 } \\
\text { (n) Patients } \\
(\mathbf{N}=6,275)\end{array}$ & $\begin{array}{c}\text { May 2007 } \\
\text { vs. Dec 2007 } \\
\text { P Value }\end{array}$ & $\begin{array}{c}\text { May 2008 } \\
\text { (n) Patients } \\
(\mathbf{N}=5,998)\end{array}$ & $\begin{array}{c}\text { May 2007. May 2008 } \\
\text { P Value }\end{array}$ & $\begin{array}{c}\text { Risk Factor Included } \\
\text { in Package Insert }\end{array}$ \\
\hline Congestive heart failureb $^{\text {a }}$ & $2.8 \%$ & $2.5 \%$ & 0.376 & $2.0 \%$ & 0.006 & $\begin{array}{l}\text { Yes-as of August 2007 } \\
\text { (black box), and prior to } \\
\text { August 2007, it was a warning. }\end{array}$ \\
\hline
\end{tabular}

a Pearson chi-square test.

${ }^{b}$ Congestive heart failure is defined as a medical claim in the prior 2 years with ICD-9-CM codes 428.xx or 398.91; the presence of congestive heart failure is a black-box warning for both rosiglitazone and pioglitazone. ${ }^{13,21}$

ICD-9-CM = International Classification of Diseases, Ninth Revision, Clinical Modification.

the national reported sales decrease of $60 \%$, or approximately 600,000 prescriptions per month between May and October 2007.20 Rosiglitazone use declined another $16.5 \%$ in 2008. In comparison, the trend in pioglitazone use was relatively flat, increasing marginally in the 2 months after the initial release of rosiglitazone CV safety concerns.

These trends between rosiglitazone and comparator products pioglitazone and sitagliptin are similar to a previous study we conducted analyzing telithromycin claims. Reports of severe liver toxicity were followed by an $80 \%$ decline in telithromycin claims between January 2006 and January 2007. Clarithromycin claims remained consistent during this period. ${ }^{21}$ However, our findings differ from those of Wilkinson et al., who found that after 2 FDA warnings, utilization of cisapride and troglitazone continued to increase. ${ }^{22}$ It was not until after 5 FDA alerts for cisapride and 4 alerts for troglitazone that utilization of cisapride and troglitazone declined significantly. The apparent quick telithromycin decline may have been due to telithromycin short-term 
$(<14$ days $)$ and episodic therapy. The rapid decline of rosiglitazone in our data may have been due to the heightened media attention associated with the Nissen and Wolski rosiglitazone meta-analysis, as opposed to FDA MedWatch alerts and label changes with cisapride and troglitazone.

Although overall utilization of rosiglitazone declined by more than 50\% during 2007, a clinically important 1 in 5 rosiglitazone users still had a CV risk factor in December 2007 and in May 2008. Of interest, greater than $50 \%$ of the at-risk rosiglitazone users were at increased risk due to their concomitant insulin therapy. A potentially safer alternative to TZD use in a population with CV risk may be insulin monotherapy, which would greatly reduce the rosiglitazone risk exposure. ${ }^{1,23}$ Given that more than 20\% of rosiglitazone users had a CV risk factor in December 2007 and in May 2008, it appears that some health care professionals have yet to act upon the information available from the FDA joint advisory committee or the November 2007 label changes.

We used pioglitazone as a comparator with rosiglitazone because it is the other FDA-approved TZD. At the time of this research, CHF was and is currently the only $\mathrm{CV}$ risk factor for pioglitazone. In our data, patients with a CHF medical claim represented 1 in 36 pioglitazone users on May 20, 2007, a prevalence rate (2.8\%) that was identical to that of rosiglitazone users, and the use of both TZDs in members with a CHF medical claim was unchanged statistically: 1 in 40 pioglitazone users and 1 in 42 rosiglitazone users in December 2007. One year after the release of data showing CV concerns with the TZDs, utilization in members with a medical claim for CHF decreased further, a change that reached statistical significance for pioglitazone ( 1 in 50 users, $P=0.006$ ). With the many alternatives to manage type 2 diabetes and the black-box warning included in the labels, we are concerned that we found members with a medical claim for CHF who continued to use a TZD.

The authors of the "2008 ADA and EASD Consensus Statement on Management of Hyperglycemia in Type 2 Diabetes" summarized their statement as follows: "In conclusion, new information suggests additional hazards associated with the use of either thiazolidinedione, and rosiglitazone, in particular, may result in an increased frequency of myocardial infarctions. We, therefore, recommend greater caution in using the thiazolidinediones, especially in patients at risk of, or with CHF." ${ }^{1}$ We agree with the consensus recommendation, and in light of our findings, we believe health care professionals and insurers should consider the impact of continued rosiglitazone use among patients at potential increased cardiac risk and take the measures they deem necessary to ensure they receive optimal, safe, and effective pharmacotherapy.

Weighing our CV risk-exposure findings, a literature review, and expert opinion, we recommended to our independent external pharmacy and therapeutics (P\&T) committee that rosiglitazone be removed from the formulary PDL. We analyzed medical and pharmacy claims data in October 2007 to determine the percentage of TZD users who had medical claims indicating increased CV risk before and after public release of the Nissen and Wolski meta-analysis. In November 2007, the P\&T committee voted to remove rosiglitazone from the national formulary PDL, and the change was effective January 1, 2008. On October 18, 2007, the U.S. Department of Veterans Affairs reported it would begin to severely limit use of rosiglitazone, and on December 6 , 2007, Health Trans reported removing rosiglitazone from their PDL due to safety concerns. ${ }^{20,24}$ This drug formulary change for rosiglitazone did not affect the status of pioglitazone on the PDL, and rosiglitazone could still be obtained via an exception process.

\section{Limitations}

The analysis was intended to explore potential associations between TZD utilization and release of the Nissen and Wolski rosiglitazone meta-analysis, FDA advisory committee meeting findings, and product label changes; hence, a direct cause-andeffect link cannot be made. Second, medical and pharmacy claims data are intended for administrative and payment purposes, and as such, they may represent information that is falsepositive or false-negative. Our analysis assumes that the medical diagnosis recorded on the claim is accurate. We did not perform either chart review or have electronic medical records available to audit the claims medical diagnosis information. However, the use of ICD-9-CM codes for identifying IHD and CHF has been found to have a high specificity $(>0.95)$ and low sensitivity $(\leq 0.76)$ when compared with chart review. ${ }^{25}$ In addition, we limited our criteria of positive identification for the presence of IHD or CHF to the primary diagnosis field. Although primary diagnosis has been found to be a more accurate predictor of the true diagnosis via chart review, ${ }^{25}$ it is possible that we missed comorbid risk factors indicated in secondary or tertiary diagnosis fields on claims for visits with a primary diagnosis of diabetes.

Third, we used the days supply field to define drug exposure as the number of days the member took the medication, from the date of service (fill date). From January 1, 2007, through May 2008, 14.2\% of pioglitazone claims, $12.6 \%$ of rosiglitazone claims, and $11.6 \%$ of sitagliptin claims had days supply of 90 or more, and a larger days supply might overestimate actual drug exposure, as well as understate the actual claims per day per million members. Actual drug exposure might also be overestimated because members may not have taken the entire days supply that was dispensed or the number of days supply may have been either estimated incorrectly or entered on the pharmacy claim incorrectly. The claim count per day per million members is understated, for example, in July and August 2007 when a 90-day supply is dispensed in June 2007, and the next refill is not dispensed until September 2007. However, this potential understatement of drug claims related to 90-day supply would be important only if there were significant changes in the proportion of 90-day versus 30-day supply for these 3 drugs over 
time, a trend that we did not find in the data. Fourth, our integrated medical and pharmacy data are also limited to a specific geographical region in the Midwest and may not be generalized to Medicare or Medicaid populations or other geographic regions. Finally, our use of a Pearson chi-square test assumes independent samples, and some of our members may have been present in multiple cohorts.

\section{Conclusions}

Rosiglitazone claims per million members declined by more than 50\% after the May 2007 CV safety concerns were publicized. However, we are concerned that some health care professionals may not be using sufficient caution when prescribing rosiglitazone because about 1 in 5 of the rosiglitazone users had a CV risk factor in December 2007 and in May 2008. About 1 in 50 pioglitazone patients had a history of CHF in their medical claims in May 2008, down from 1 in 36 pioglitazone patients in May 2007. Given the confluence of information surrounding rosiglitazone use in high-risk members and the many disadvantages now known to be associated with TZDs, some managed care organizations have removed rosiglitazone from preferred placement on their formularies. Two other managed care methods to safeguard members from high-risk medications are retrospective drug utilization programs (RetroDUR) to inform prescribers and concurrent utilization management programs such as prior authorization or step-therapy. Health care professionals need to reassess continued TZD use, and especially rosiglitazone use, on a patient-by-patient basis. Insurers should consider the impact of persistent rosiglitazone use among members at potentially increased cardiac risk and should take the necessary measures to ensure that their members receive optimal safe and effective pharmacotherapy. Further study should be done to confirm TZD use among high-risk patients, and whether this use is associated with increased adverse medical events and health care expenditures.

\section{DISCLOSURES}

There was no external funding for this research. The authors report no conflicts of interest associated with this research. Catherine I. Starner and Patrick P. Gleason developed the study concept and design and were responsible for data collection. Data interpretation and writing of the manuscript were the work of all authors. Starner, with assistance from Gleason, made the majority of revisions to the manuscript.

\section{ACKNOWLEDGMENTS}

The authors wish to thank Steve Schlichtmann, MBA, senior systems developer, Prime Therapeutics, for his help with data retrieval and analysis.

\section{REFERENCES}

1. Nathan DM, Buse JB, Davidson MB, et al. Management of hyperglycemia in type 2 diabetes: a consensus algorithm for the initiation and adjustment of therapy. Diabetes Care. 2008;31:173-75.

\section{Authors}

CATHERINE I. STARNER, PharmD, BCPS, CGP, is Senior Clinical Pharmacist, Prime Therapeutics LLC, Eagan, Minnesota, and Adjunct Assistant Professor, University of Minnesota College of Pharmacy, Minneapolis. JEREMY A. SCHAFER, PharmD, is Manager of Formulary Development, Prime Therapeutics, LLC, Eagan, Minnesota. ALAN H. HEATON, PharmD, is Director of Pharmacy, BlueCross BlueShield of Minnesota, Eagan, Minnesota, and Assistant Professor in the Graduate School of Public Health, University of Minnesota, Minneapolis. PATRICK P. GLEASON, PharmD, BCPS, FCCP, is Director, Outcomes Assessment, Prime Therapeutics LLC, Eagan, Minnesota, and Adjunct Associate Professor, University of Minnesota College of Pharmacy, Minneapolis.

AUTHOR CORRESPONDENCE: Patrick P. Gleason, PharmD, BCPS, FCCP, Director, Outcomes Assessment, Prime Therapeutics, 1305 Corporate Center Dr., Eagan, MN 55121. Tel.: 651.286.4190; E-mail:pgleason@primetherapeutics.com

2. Drug Topics. Available at: www.drugtopics.com/Top+200+Drugs. Accessed December 31, 2007.

3. Irons BK, Green RS, Mazzolini TA, Edwards KL, Sleeper RB. Implications of rosiglitazone and pioglitazone on cardiovascular risk in patients with type 2 diabetes mellitus. Pharmacotherapy. 2006;26:168-81.

4. Choi D, Jang Y, Kim SK, et al. Preventative effects of rosiglitazone on restenosis after coronary stent implantation in patients with type 2 diabetes. Diabetes Care. 2004;27:2654-60.

5. Marx N, Wohrle J, Nusser T, et al. Pioglitazone reduces neointima volume after coronary stent implantation. A randomized, placebo-controlled, double-blind trial in nondiabetic patients. Circulation. 2005;112:2792-98.

6. Dormandy JA, Charbannel B, Eckland DA, et al. Secondary prevention of macrovascular events in patients with type 2 diabetes in the PROactive study (prospective pioglitazone clinical trial in macrovascular events): a randomized controlled trial. Lancet. 2005;366:1279-89.

7. U.S. Food and Drug Administration. Label and approval history for Avandia. Available at: www.accessdata.fda.gov/scripts/cder/drugsatfda/index cfm?fuseaction=Search.Label_ApprovalHistory. Accessed June 13, 2008.

8. Avandia (rosiglitazone) [package insert]. Philadelphia, PA: SmithKline Beecham Pharmaceuticals; 1999. Available at: www.fda.gov/cder/foi/label/ 1999/21071lbl.pdf. Accessed June 20, 2008

9. U.S. Food and Drug Administration. Label and Approval History for Actos. Available at: www.accessdata.fda.gov/scripts/cder/drugsatfda/index. $\mathrm{cfm}$ ?fuseaction=Search.Label_ApprovalHistory\#apphist. Accessed June 13, 2008.

10. Actos (pioglitazone) [package insert]. Lincolnshire, IL: Takeda Pharmaceuticals America, Inc.; 1999. Available at: www.fda.gov/cder/foi/ label/1999/21073lbl.pdf. Accessed June 20, 2008.

11. Nesto RW, Bell D, Bonow RO, et al. Thiazolidinedione use, fluid retention, and congestive heart failure. A consensus statement from the American Heart Association and American Diabetes Association. Diabetes Care. 2004;27:256-63.

12. Nissen SE, Wolski K. Effect of rosiglitazone on the risk of myocardial infarction and death from cardiovascular causes. N Engl J Med. 2007; 356(24):2457-71. Available at: http://content.nejm.org/cgi/content/abstract/ 356/24/2457. Accessed June 20, 2008. 
13. Glaxo Smith Kline. Study No.: ZM2005/0018/01: Avandia Cardiovascular Event Modeling Project Study No.: HM2006/00497/00/ WEUSRTP866: Coronary Heart Disease Outcomes in Patients Receiving Antidiabetic Agents. Available at: http://ctr.gsk.co.uk/Summary/ Rosiglitazone/III_CVmodeling.pdf. Accessed July 7, 2008.

14. Division of Metabolism and Endocrine Products and Office of Surveillance and Epidemiology, U.S. Food and Drug Administration. FDA Briefing Document: joint meeting of the Endocrinologic and Metabolic Drugs Advisory Committee held on July 30, 2007. Available at: www.fda. gov/ohrms/dockets/ac/07/briefing/2007-4308bl-02-fda-backgrounder.pdf. Accessed October 12, 2007.

15. Rosen CJ. The rosiglitazone story-lessons from an FDA advisory committee meeting. N Engl J Med. 2007;357(9):844-46.

16. U.S. Food and Drug Administration Center for Drug Evaluation and Research. Summary minutes of the joint meeting of the Endocrinologic and Metabolic Drugs Advisory Committee and the Drug Safety and Risk Management Advisory Committee held on July 30, 2007. Available at: www.fda.gov/ohrms/dockets/ac/07/minutes/2007-4308ml-final.pdf. Accessed December 27, 2007.

17. Avandia (rosiglitazone) [package insert]. Research Triangle Park, NC: GlaxoSmithKline; 2007.

18. U.S. Food and Drug Administration. Label and approval history for Januvia. Available at: www.accessdata.fda.gov/scripts/cder/drugsatfda/ index.cfm?fuseaction=Search.Label_ApprovalHistory\#apphist. Accessed June 13, 2008.

19. U.S. Food and Drug Administration. Label and approval history for Janmet. Available at: www.accessdata.fda.gov/scripts/cder/drugsatfda/ index.cfm?fuseaction=Search.Label_ApprovalHistory\#apphist. Accessed June 13, 2008.

20. Saul S. VA is limiting use of diabetes drug. New York Times. October 18, 2007. Available at: www.nytimes.com/2007/10/18/business/18drug.html?ex= 1350360000 \&en $=06879$ a6ee $6369532 \&$ \&ei $=5088 \&$ partner $=$ rssnyt \&emc $=r s s$. Accessed June 13, 2008.
21. Gleason PP, Walters C, Heaton AH, Schafer JA. Telithromycin: the perils of hasty adoption and persistence of off-label prescribing. J Manag Care Pharm. 2007;13(5):420-25. Available at: www.amcp.org/data/jmcp/ JMCPMaga_June\%2007_p420-425.pdf.

22. Wilkinson JJ, Force RW, Cady PS. Impact of safety warnings on drug utilization: marketplace life span of cisapride and troglitazone. Pharmacotherapy. 2004;24:978-86.

23. Rosenstock J, Sugimoto D, Strange P, Stewart JA, Soltes-Rak E, Dailey G. Triple therapy in type 2 diabetes. Insulin glargine or rosiglitazone added to combination therapy of sulfonylurea plus metformin in insulin-naive patients. Diabetes Care. 2006;29:554-59.

24. Reuters. Two U.S. healthcare providers drop Glaxo's Avandia. Available at: www.reuters.com/article/idUSL0626857620071206. Accessed December 13, 2007.

25. Birman-Deych E, Waterman AD, Yan Y, et al. Accuracy of ICD-9-CM codes for identifying cardiovascular and stroke risk factors. Med Care. 2005;43:480-85.

26. FDA News. FDA issues safety alert on Avandia. Available at: www.fda.gov/bbs/topics/NEWS/2007/NEW01636.html. Accessed June 13, 2008.

27. FDA News. Manufacturers of some diabetes drugs to strengthen warning on heart failure risk. Available at: www.fda.gov/bbs/topics/NEWS/2007/ NEW01683.html. Accessed June 13, 2008.

28. FDA. Information for healthcare professionals. Rosiglitazone maleate (marketed as Avandia, Avandamet, and Avandaryl). Available at: www.fda.gov/cder/drug/InfoSheets/HCP/rosiglitazone200707HCP. htm\#2007_5. Accessed June 13, 2008. 